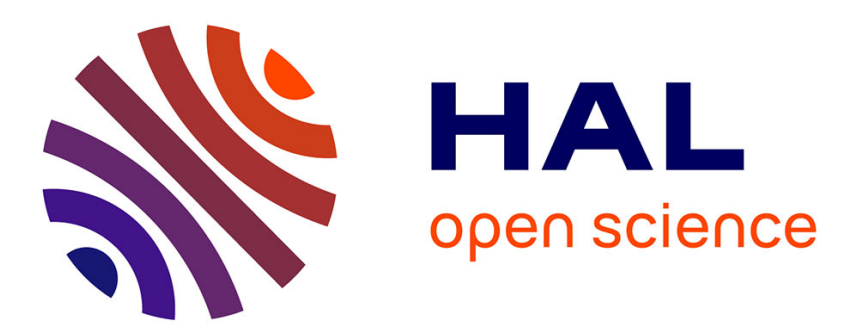

\title{
Similar time distortions under the effect of emotion for durations of several minutes and a few seconds.
}

Sylvie Droit-Volet, Ahmed El-Azhari, Samuel Haddar, Rémi Drago, Sandrine

Gil

\section{- To cite this version:}

Sylvie Droit-Volet, Ahmed El-Azhari, Samuel Haddar, Rémi Drago, Sandrine Gil. Similar time distortions under the effect of emotion for durations of several minutes and a few seconds.. Acta Psychologica, 2020, 210, 10.1016/j.actpsy.2020.103170 . hal-02921149

\section{HAL Id: hal-02921149 \\ https://hal.science/hal-02921149}

Submitted on 10 Nov 2020

HAL is a multi-disciplinary open access archive for the deposit and dissemination of scientific research documents, whether they are published or not. The documents may come from teaching and research institutions in France or abroad, or from public or private research centers.
L'archive ouverte pluridisciplinaire HAL, est destinée au dépôt et à la diffusion de documents scientifiques de niveau recherche, publiés ou non, émanant des établissements d'enseignement et de recherche français ou étrangers, des laboratoires publics ou privés. 
Droit-Volet, S., El-Azhari, A., Haddar, S., Drago, R., \& Gil, S. (2020). Similar time distortions under the effect of emotion for durations of several minutes and a few seconds. Acta Psychologica, 210, 103170.

\title{
Similar time distortions under the effect of emotion for durations of several minutes and a few seconds
}

\author{
Sylvie Droit-Volet ${ }^{a}$, Ahmed El-Azharia ${ }^{a}$ Samuel Haddara, Rémi Drago ${ }^{a}$, Sandrine Gil ${ }^{b}$ \\ ${ }^{a}$ Université Clermont Auvergne, CNRS, UMR 6024, Clermont-Ferrand, France \\ ${ }^{\mathrm{b}}$ Université de Poitiers, CNRS, UMR 7295, Poitiers, France
}

Corresponding author : Sylvie Droit-Volet - Université Clermont Auvergne, Laboratoire de Psychologie Sociale et Cognitive (LAPSCO), CNRS, UMR 6024, 34 avenue Carnot, 63037 Clermont-Ferrand, France.

E-mail address: sylvie.droit-volet@uca.fr (S. Droit-Volet).

\section{A B S T R A C T}

This study examined the effect of emotion on the judgment of durations of several minutes compared with that of durations of a few seconds. Three experiments were performed on the temporal judgment of emotional stimuli lasting from $2 \mathrm{~s}$ to 6 min (Experiment 1) or from 2 to 6 min (Experiment 2 and 3 ). These involved emotional sounds (Experiment 1 and 2) or virtual reality emotional films (Experiment 3 ). The results showed an increase in the lengthening of the perceived duration as the level of arousal and negative valence of the emotional stimuli increased, both for the long durations of several minutes and for the shorter durations. However, the magnitude of the time distortion tended to decrease as the length of the duration increased because the affects experienced by the participants lost their intensity over time. Nonetheless, when the exposure to emotional stimuli was limited and the stimuli were sufficiently arousing, as in Experiments 2 and 3 , people overestimated time across durations ranging from seconds to minutes. 


\section{Introduction}

We have long known that our sense of time varies according to our affects. As early as 1890, the philosopher Guyau (1890) stated that the "estimation of durations is simply a question of internal optics... related to the emotion of pleasure and pain" (p. 85-86). Occasional studies in psychology have highlighted this phenomenon (Angrilli et al., 1997; Falk \& Bindra, 1954; Hare, 1963; Langer et al., 1961; Thayer \& Schiff, 1975). However, since the 2000s, we have witnessed an explosion in the number of studies on emotion and time judgment (for reviews, see Droit-Volet, 2019; Droit-Volet \& Meck, 2007; Lake, 2016). Several temporal tasks have therefore been tested, in particular the temporal bisection task (e.g., Buetti \& Lleras, 2012; Doi \& Shinohara, 2009; DroitVolet et al., 2004; Droit-Volet \& Gil, 2016; Grommet et al., 2010; Liu et al., 2015; Tipples, 2008, 2011), the temporal reproduction task (e.g., Bar-Haim et al., 2010; Lambrech et al., 2011; Lee et al., 2011; Mella et al., 2010; Noulhiane et al., 2007; Van Volkinburg \& Balsam, 2014), and the verbal estimation task (e.g., Gil \& Droit-Volet, 2011; Ogden et al., 2019). A wide variety of emotional stimuli have also been examined, such as emotional facial expressions, pictures from the International Affective Picture System (IAPS - Lang et al., 1999), sounds from the International Affective Digitized Sounds System (IADS Bradley \& Lang, 2007) or even electro-cutaneous stimulation (e.g.,
Fayolle et al., 2015; Piovesan et al., 2018). However, although many experiments have been conducted in this field, they have all focused on the study of short durations in the milliseconds to seconds range. There are indeed very few experimental studies on the judgment of long durations of several minutes (Droit-Volet et al., 2018; Rau et al., 2006; Tobin et al., 2010; Tobin \& Grondin, 2009) and none on the temporal judgment of emotional stimuli in this duration range. This is surprising because events or activities in everyday life often last for several minutes. The aim of our study was therefore to compare the time judgment of emotional stimuli for long durations of several minutes with that of short durations.

Studies on the relationship between emotion and judgments of short durations have systematically found that the elapsed duration is judged to last longer with High-Arousal (HA) emotional stimuli than with LowArousal (LA) or neutral emotional stimuli. This lengthening of perceived duration produced by emotional arousal has been found in young children (Droit-Volet et al., 2016; Gil et al., 2007), as well as in tasks of implicit time judgment (Droit-Volet, 2016; Droit-Volet \& Berthon, 2017), suggesting that it is an automatic stimulus-driven process. It has also been observed for different emotions (fear, anger, disgust) with similar arousal ratings (Droit-Volet et al., 2011; Kliegl et al., 2015; Lambrech et al., 2011). The consistency of the results on the effect of emotional arousal on timing has led researchers to argue 
that changes in arousal levels are the main source of time distortions (Cheng et al., 2016; Gil \& Droit-Volet, 2012; Lake et al., 2016; Mella et al., 2010).

The short durations perceived longer in the case of highly arousing stimuli has been explained by the physiological activation that speeds up the internal clock system that provides the raw material for the representation of time. When the internal clock speeds up, more time units (pulses, oscillator rate) are produced, and the longer the stimulus duration is judged to be. Changes in dopaminergic activity in the brain would account for this speeding up of the internal clock system (Cheng et al., 2016; Simen \& Matthew, 2016; Soares et al., 2016). Stress and threat would induce changes in phasic dopamine level in the cortex and the striatum. These changes in turn would increase the frequency of oscillation of cortical neurons detected by the striatum (Matell \& Meck, 2004).

The explanation of emotional effects on time distortions solely in terms of mechanisms related to physiological arousal is debatable if we consider different duration lengths. Furthermore, such an explanation does not take account of the real and complex nature of emotion, i.e. its ephemeral and multi-component nature. Very few studies have compared the effects of emotional stimulus presentation on the perception of times of different duration values, including long durations of several seconds (e.g., Angrilli et al., 1997; Bar-Haim et al., 2010; Noulhiane et al., 2007), and none, to our knowledge, has focused on durations in the minutes range. These few studies nevertheless suggest that the arousal effect on time distortions observed with short durations disappears with longer durations ( $>4 \mathrm{~s}$ ). For example, Angrilli et al. (1997) asked their participants to verbally estimate or reproduce the duration of emotional IAPS slides lasting for 2, 4 and $6 \mathrm{~s}$. They found a temporal overestimation at $2 \mathrm{~s}$ for high-arousal slides. However, this effect disappeared at $4 \mathrm{~s}$ and was even reversed at $6 \mathrm{~s}$, resulting in a temporal underestimation. Using similar tasks but with auditory emotional stimuli, Noulhiane et al. (2007) also observed no emotional effect on the judgment of durations of 4 or $6 \mathrm{~s}$, while the 2-s sounds were judged longer when they were high-arousal negative stimuli than when they were neutral or low-arousal. These findings led the authors to state that the temporal judgment of emotional stimuli appears to be based on an "emotionally driven mechanism", i.e. one that depends on physiological arousal level, only for short stimulus durations (Angrilli et al., 1997, p. 979). For long durations, it would depend on later cognitive mechanisms (see Fig. 7.3, Droit-Volet, 2019).

An emotion can indeed not be reduced to its (neuro)physiological manifestations, especially for long durations. Some authors speak about "emotional episodes" involving a dynamic of different components and processes (Scherer \& Moors, 2019). With the passage of time, cognitiveexperiential components (i.e., subjective awareness, reporting emotion) could thus appear and modify the initial effects related to arousal. This is why some authors question the existence of physiological correlates and their impact as soon as self-reported conscious emotions are involved (Barrett, 2006; Mauss \& Robinson, 2009). In the timing field, Cocenas-Silva et al. (2019) showed, for example, that the variations in the judgment of non-emotional durations of several seconds $(4 \mathrm{~s})$ by some participants under stress (nurses working in an emergency situation) were related to cognitive component of stress, i.e., perceived stress, rather than physiological stress. Other studies have collected physiological indexes of arousal in the activity of the autonomic nervous system (ANS) and have observed a significant correlation between time judgments under stressful conditions and changes in the measured physiological indexes (Skin Conductance, heart rate), but only for the short durations (<2 s) (Ogden et al., 2019; Piovesan et al., 2018; van Hedger et al., 2017). Furthermore, even when there was a relation between ANS activation and the perceived short durations, the ANS activation only accounted for a small proportion of the variance in perceived duration, thus suggesting that other factors contribute to time distortions (Piovesan et al., 2018). Therefore, due to the dynamic evolution of emotions over time, different mechanisms could underlie the effect of the same emotional stimulus on the judgment of durations depending on the range of durations considered, from a few seconds to several minutes (Droit-Volet, 2019).

To start filling the gap in experimental research on the timing of long durations, Droit-Volet et al. (2018) conducted a first study on the judgment of long intervals (from 2 to $8 \mathrm{~min}$ and from 8 to $32 \mathrm{~min}$ ) in everyday life using the Experience Sampling Methodology (ESM). In this study, the participants had to estimate the temporal interval between two beeps, an interval during which they carried on with their daily activities. They also reported their affective feelings after each interval. The results showed a significant correlation between the subjective level of arousal reported by the participants and their temporal judgment of long duration. The subjective component of emotion (the reported emotional experience) could therefore be a significant factor in time distortions for long durations rather than the physiological arousal triggered by an emotional stimulus, which quickly loses its effect on timing, as described above. In addition, in this study, which was conducted in a real-life context, the interval durations were judged longer when the self-reported level of arousal decreased, but not when it increased as is shown by the emotional arousal effects for the short durations. This study thus suggests that a reversal of the effect of emotions on time judgment might be possible when long durations are involved. However, these original results were obtained in a correlation study conducted in an everyday life context.

The aim of the present study was thus to experimentally test in three laboratory studies the causal effect of highly arousing emotional stimuli on the judgment of long durations going from few seconds to several minutes, i.e. between $2 \mathrm{~s}$ and $6 \mathrm{~min}$. In addition, in our studies, for each trial, we recorded the subjective level of arousal and the pleasantness felt by the participants during the target duration. We have therefore given ourselves the means to examine the association between the estimation of durations of emotional stimuli and their subjective affective assessment. Experiment 1 tested several time ranges in order to compare them directly (2-6 s, 20-60 s and 2-6 min), while Experiments 2 and 3 focused on the under-investigated longest time range of several minutes (2-6 min). In addition, to ensure that the emotional stimuli were sufficiently arousing to affect timing during a long interval, we tested specific continuous auditory stimuli (Experiment 1 and 2) as well as immersion in a virtual reality (VR) environment (Experiment 3).

\section{Experiment 1}

\subsection{Method}

\subsubsection{Participants}

The participants were 87 (68 female) students from Clermont Auvergne University, France $\left(\mathrm{M}_{\text {age }}=26.218\right.$ years, $\left.S D=4.10\right)$. They each signed a written informed consent form containing a description of the procedure, in accordance with the principles of the Declaration of Helsinki and with the approval of the statutory ethics committee (CPP France).

\subsubsection{Material}

The participants were seated in a quiet room facing a computer that delivered and recorded all the experimental events using E-Prime (Psychology Software Tools Inc., Sharpsburg, PA, USA). They responded by pressing a key on a numeric keypad. To ensure that the emotional stimuli used for durations between $1 \mathrm{~s}$ and $8 \mathrm{~min}$ had similar characteristics, we decided to construct 8-min stimuli with Audacity software on the basis of sounds from the IADS (Bradley \& Lang, 2007), by repeating sections of the original stimulus. Noulhiane et al. (2007) used a similar procedure for their 4- and 6-s IADS stimulus. Each emotional stimulus therefore took the form of a longer or shorter exposure to an original IADS sound without any inter-sound delay in order to ensure the uninterrupted flow of the auditory stimulus. For example, the 8-min stimulus (Attack1, $n^{\circ} 279$ ) was the continuous 
sound of a battered woman's cries. For each testing trial, the participants assessed the emotional valence (pleasure) and the arousal level of

the emotional stimuli used. They gave their ratings on a 9-point scale based on Bradley and Lang's (1994) scale used in the validation of IADS stimuli. A first scale was used for arousal level and went from Calm/ Relaxed/Weakly aroused to Stimulated/Alert/Highly aroused, and a second scale was used for emotional valence and went from Joyfull Satisfied/Happy to Not-Joyful/Not-satisfied/Annoyed/Unhappy. The participants responded by pressing a number between 1 and 9 on the numeric keypad.

As there are no neutral sounds in the IADS, we decided to use five different sounds for each of the three different arousal levels: HA ( ${ }^{\circ}$ $275,279,285,286,712)$, moderate arousal (MA) $\left(n^{\circ} 320,403,425\right.$, $500,729)$ and LA ( $\left.{ }^{\circ} 172,262,698,809,812\right)$.

\subsubsection{Procedure}

The participants were assigned to one of three groups, each with a different stimulus-duration range: 2-6 s, 20-60 s, and 2-6 min. In each group, they were exposed to five durations: three target durations and two additional lure durations, which were used to vary the value of the durations to be estimated. These two additional durations were randrolly chosengetyeen 1 and 12 s for the $226-\mathrm{s}$ group botween 19 and group. The participants were told that the sounds would last between 1

and $12 \mathrm{~s}, 10$ and $120 \mathrm{~s}$, and 1 and $12 \mathrm{~min}$, respectively. The target durations were 2, 4 and $6 \mathrm{~s}, 20,40$ and $60 \mathrm{~s}$, and 2, 4 and $6 \mathrm{~min}$, respectively. Because participants may use counting to assist their responses, thereby achieving greater accuracy but disrupting the scalar properties of timing (Wearden \& Lejeune, 2008), they were also instructed that they should not attempt to estimate the duration by counting so as not to skew the scientific results - although this would have been impossible for long durations of several minutes. This instruction is the one of the most effective methods to prevent counting during timing protocols (Rattat \& Droit-Volet, 2012).

The procedure was similar for each duration group. The participants completed 45 trials divided into 3 successive blocks of 15 trials each: i.e., one trial for each duration (5 durations: 3 target and 2 lure durations) in the three emotional conditions (HA, MA and LA) $(3 \times 5 \times 3)$. The trial order was random within each trial block. For each trial, the emotional stimulus was also randomly chosen from the set of five emotional sounds. For each trial, after a random inter-trial interval, the word prêt [ready] appeared in the center of the computer screen and the participants initiated the trial by pressing the spacebar on the keyboard.

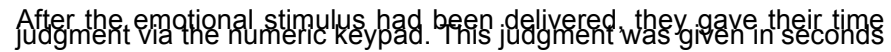
for the 2/6-s and the 20/60-s groups, and in minutes and seconds for

the 2/6-min group. They then assessed the affective dimensions of the emotional stimulus in terms of arousal and emotional valence.

\subsection{Results and discussion}

\subsubsection{Assessment of the emotional stimuli}

2.2.1.1. Arousal. Fig. 1 shows the mean scores of self-reported arousal level for the emotional stimuli presented during the different testing durations in the three duration range conditions. An ANOVA was performed on the arousal scores, with two within-subjects factors (emotion, stimulus duration) and one between-subjects factor (duration range).

This ANOVA showed a significant main effect of emotion, $F(2$, $168)=470.01, p=.001, \eta_{p}^{2}=0.85$, confirming that the HA emotional stimuli $(M=7.37, S E=0.13)$ were judged to be more arousing than either the MA $(M=4.99, S E=3.39)$ or the LA $(M=3.39, S E=0.11)$ emotional stimuli (Bonferroni, all $p s<0.0001)$. The MA stimuli were also judged to be more arousing than the LA stimuli $(p<.0001)$.

However, the presentation duration of the emotional stimuli also affected the level of arousal reported. There were indeed significant effects of duration range, $F(2,84)=28.85, p=.0001, \eta^{2}=0.41$, stimulus duration, $F(2,168)=3.62, p=.03, \eta_{p}^{2}=.04$, and of the interaction between these two factors, $F(4,168)=3.05, p=.02$, $\eta_{p}^{2}=0.07$. The overall arousal scores were lower for the durations in the minutes range $(M=4.27, E S=0.16)$ than for those in the $2 / 6$-s $(M=5.90, E S=0.16)$ or the 20/60-s $(M=5.58, E S=0.17)$ duration ranges (Bonferroni, $p<.05$ ), while no difference was observed between the two shorter duration ranges $(p>.05)$. Moreover, the arousal scores did not vary with the stimulus duration for the $2 / 6$ and the 20/60-s ranges $(F(2,58)=0.18, F(2,52)=0.38$, respectively, both $p>$.10), while they decreased as the stimulus duration increased in the minutes ranges, as revealed by the significant linear stimulus duration effect, $F(2,51)=9.25, p=.005, \eta_{p}^{2}=0.24$.

Similarly, the ANOVA found a significant interaction between emotion and duration range, $F(4,168)=2.51, p=.04, \eta_{p}^{2}=0.6$, and between emotion and stimulus duration, $F(4,336)=12.60, p=.001$, $\eta_{p}^{2}=0.13$. However, the three-way interaction was not significant, $F(8$, $336)=0.69, p=.69$. There was indeed a significant effect of emotion in the three duration ranges $(2 / 6 \mathrm{~s}: F(2,58)=260.63 ; 20 / 60 \mathrm{~s}: F(2$, $52)=266.26 ; 2 / 6 \min : F(2,58)=75.95$, all $p s=.0001)$. However, for each type of emotional stimuli taken separately (HA, MA, LA), the

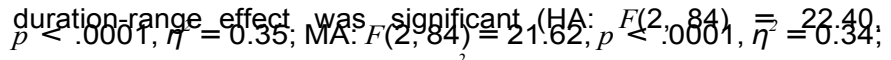
LA: $\left.F(2,84)^{p}=9.83, p<.0001,{ }_{p} \eta^{2}=0.19\right)$, indicating that the participants experienced a lower level of arousal with the long durations than with the shorter ones, although the difference in the arousal scores between stimulus durations was smaller for the LA emotional stimuli.

2.2.1.2. Emotional pleasure. For the pleasure scores, there was also a significant main effect of emotion, $F(2,168)=454.07, p=.001$, $\eta_{p}^{2}=0.84$, with the HA $(M=7.82, S E=0.10)$ being judged more unpleasant than the MA $(M=5.25, S E=0.10)$ or the LA $(M=4.11$, $S E=0.12$ ) emotional stimuli. The MA stimuli were also judged to be less pleasant than the LA stimuli (Bonferroni, all $p \mathrm{~s}=.0001)$. The main effect of duration range was also significant, $F(2,84)=6.08, p=.003$, $\eta_{p}^{2}=0.13$, with no effect of stimulus duration, $F(2,168)=1.25$, $p=.29$ (Fig. 2). The negative valence of the emotional stimuli was therefore experienced as being weaker for long durations of several minutes than for shorter durations of only a few seconds $(p=.003)$, with no difference being found between the 20/60-s and 2/6-s durations $(p>.05)$. However, there was also a significant emotion $\times$ duration range interaction, $F(4,168)=2.95, p=.02$, $\eta_{p}^{2}=0.07$, but no other significant interaction. The effect of emotion on

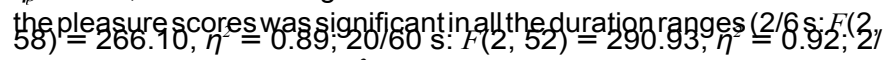
6 min: $F(2,58) \stackrel{p}{=}=70.93,{ }_{p}^{\eta^{2}}=0.71$, all $\left.p \mathrm{~s}=.0001\right)$. The significant interaction therefore indicates that the unpleasantness of the emotional stimuli decreased as the length of the durations increased.

In sum, the statistical analyses of the affective ratings confirmed that hearing the HA emotional sounds was felt to be more arousing and less pleasant than hearing the MA or the LA emotional sounds for the different presentation durations used in our study, which went from a few seconds to several minutes. However, the level of arousal and pleasure experienced by the participants decreased as the length of the durations increased.

\subsubsection{Temporal performance}

2.2.2.1. Temporal standard error. For each trial, we calculated the temporal standard error, that is, the difference between the time estimate and the target duration, divided by the target duration. A temporal standard error equal to zero indicates an accurate temporal judgment. A temporal standard error less than or longer than 1 indicates an under- and over-estimation, respectively, of the target duration. The ANOVA performed on this index with the 3 factors described above (emotion, stimulus duration, duration range) showeda significant main effect of duration range, $F(2,84)=24.30, p=.001$, 


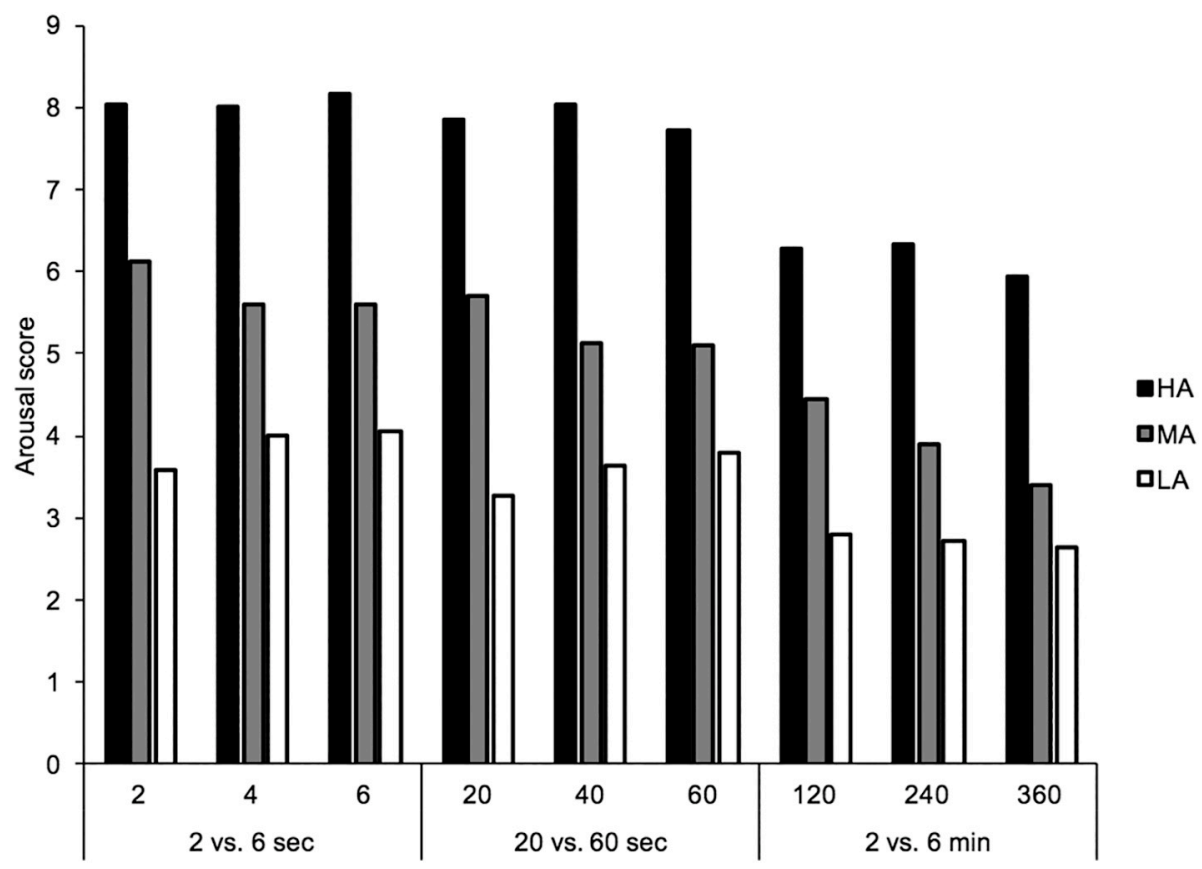

Fig. 1. Mean arousal scores for the High-Arousal (HA), the Moderate-Arousal (MA), and the Low-Arousal (LA) emotional stimuli for the different stimulus duration in the 2 vs. 6 -sec, the 20 vs. $60-\mathrm{sec}$, and the 2 vs. 6-min duration groups.

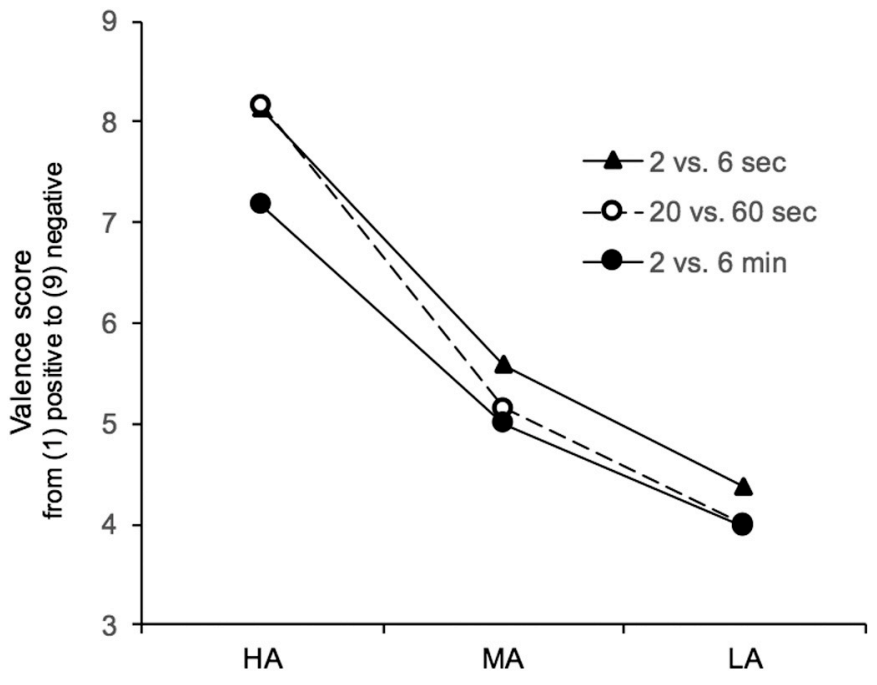

Fig. 2. Mean valence scores (from 1 positive to 9 negative valence) for the HighArousal (HA), the Moderate-Arousal (MA), and the Low-Arousal (LA) emotional stimuli for the 2 vs. $6-\mathrm{sec}$, the 20 vs. $60-\mathrm{sec}$, and the 2 vs. 6 -min duration groups.

$\eta_{p}^{2}=0.37$. As indicated in Fig. 3, the stimulus durations were overestimated in the minutes range compared with the seconds ranges (Bonferroni, all $p s=.001$ ), while no difference in timing was observed between the two shorter duration conditions $(p=.75)$. Furthermore, the ANOVA found a significant main effect of stimulus duration, $F(2,168)=25.13, p=.001, \eta_{p}^{2}=0.23$, and a significant stimylus, dukation $\times$ duration range interaction $F(4,168)_{i f}=9937$

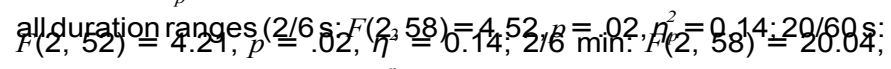
$\left.p=.001, \eta_{p}^{2}=0.41\right)$, indicating that the shortest durations within a duration range tended to be overestimated compared with the longest ones. This finding is consistent with Vierordt's law. However, the magnitude of the difference between the stimulus durations was

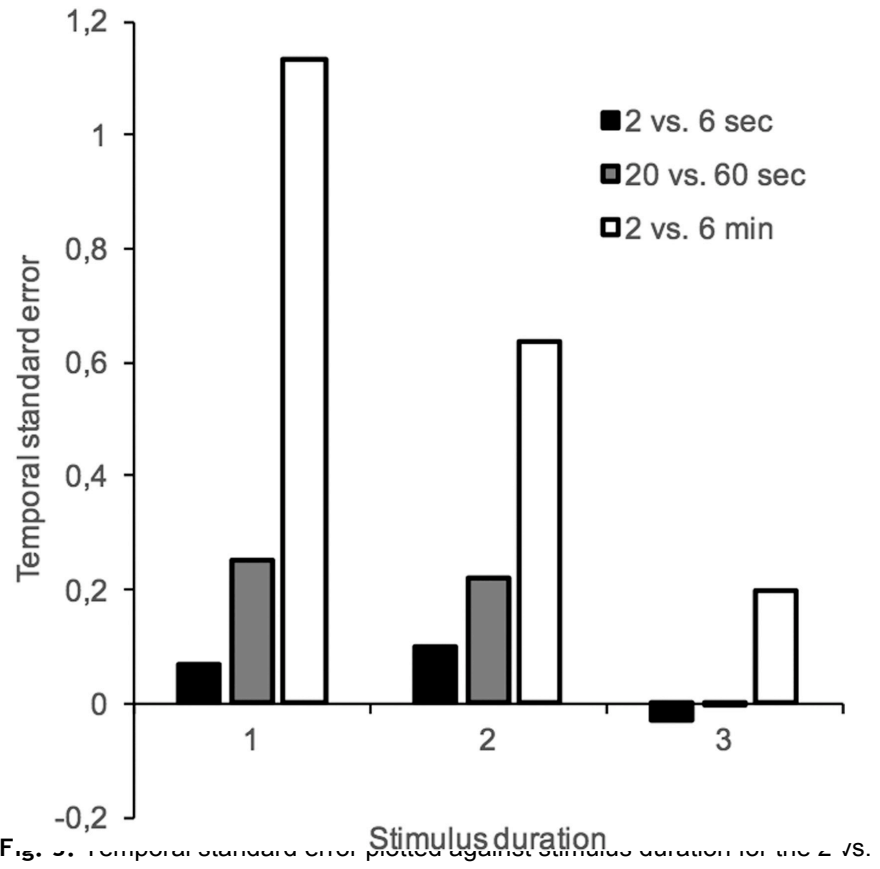

6 -sec, the 20 vs. $60-\mathrm{sec}$, and the 2 vs. 6 -min duration groups.

greater in the range of very long durations lasting several minutes. Our results on long durations thus replicated those of studies on the timing of long durations (Droit-Volet et al., 2018).

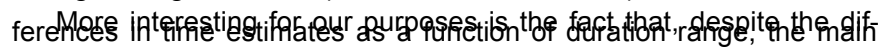

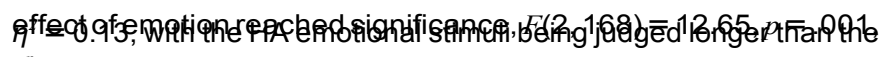
MAand the LAemotional stimuli (Bonferroni, $p=.001$ ). Nodifference was observed between the MA and the LA emotional stimuli $(p>.05)$ (Fig. 4). However, there was a significant emotion $\times$ duration range interaction, $F(4,168)=2.83, p=.03, \eta_{p}^{2}=0.63$. No other interaction 


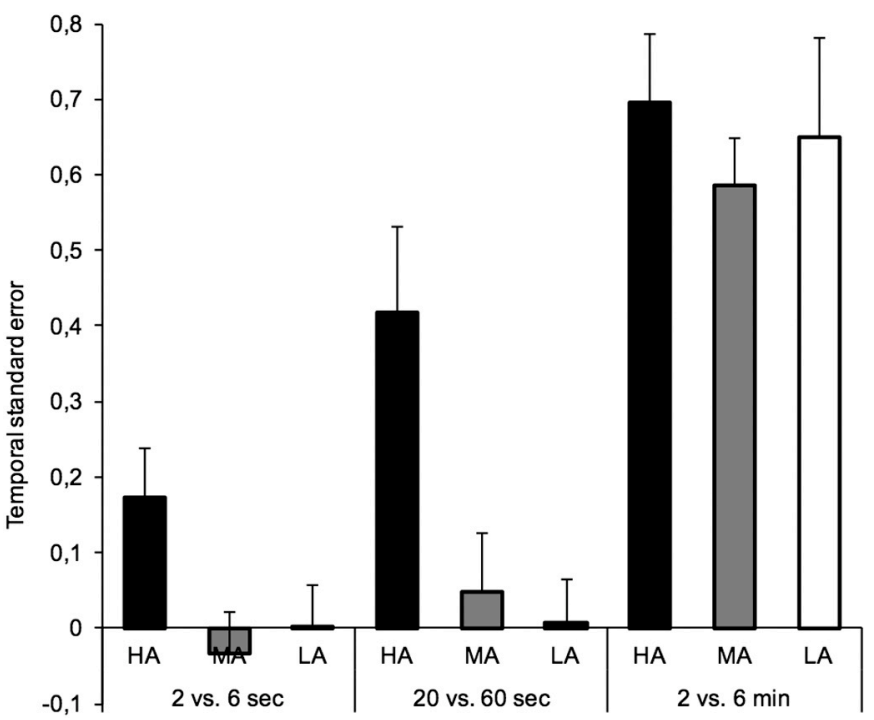

Fig. 4. Temporal standard error plotted against the High-Arousal (HA), the Moderate-Arousal (MA), and the Low-Arousal (LA) emotional stimuli for the 2 vs. 6 -sec, the 20 vs. $60-\mathrm{sec}$, and the 2 vs. 6 -min duration groups.

involving the emotion factor was significant (all $p s>.05)$. The effect of emotion was significant in the $2 / 6-\mathrm{s}, F(2,58)=38.54, p=.001$, $\eta_{p}^{2}=.57$, and the 20/60-s group, $F(2,52)=13.76, p=.001$, $\eta_{p}^{2}=0.35$, but failed to reach significance in the 2/6-min group, $F(2$, $58)=0.53, p>.05$. In this last group, the HA emotional stimuli were only judged to be longer than the MA emotional stimuli for the shortest stimulus duration $(2 \mathrm{~min}), t(29)=2.062, p=.04$. By contrast, in the other duration groups, the $\mathrm{HA}$ stimuli were judged to be longer than the MA and LA stimuli for all stimulus durations $(p<.05)$, with no difference being observed between the LA and the MA emotional stimuli $(p>.05)$.

2.2.2.2. Temporal variability $(S D)$ of time estimates. We also ran an ANOVA on the variability $(S D)$ of time estimates. This ANOVA failed to reveal a significant main effect of emotion, $F(2,168)=0.19, p=.83$, an emotion $\times$ duration range interaction, $F(4,168)=0.73, p=.57$, or any other interaction involving the emotion factor $(p>.05)$. Accordingly, differences in the emotional stimuli affected the length of the time estimates, but not their variability, as has been observed in most studies on emotion and time perception, at least in an HA context (for a review, see Droit-Volet, Fayolle, Lamotte, \& Gil, 2013). The ANOVA on temporal variability only confirmed the classical results on timing indicating that the scalar properties of time hold for a wide range of durations going from a few seconds to several minutes (Fig. 5). There was indeed a significant duration range effect, $F(2,84)=90.62$, $p=.001, \eta_{p}^{2}=0.68$, indicating that the variability of estimates increased as the duration ranges lengthened (1.09 vs. 13.65 vs.

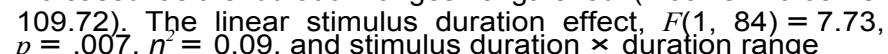
interaction, $\stackrel{p}{F}(2,84)=4.91, p=.01, \quad \eta_{p}^{2}=0.11$, were also significant. As suggested in Fig. 5 , the temporal variability increased with the stimulus duration in each duration condition taken separately,

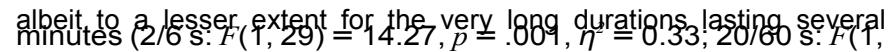
26) $=10.93, p=.003,{ }_{p}^{2}=0.29 ; 2 / 6 \min , \underset{p}{p}(1,29)=6.11, p=.02$, $\left.\eta_{p}^{2}=0.17\right)$.

\subsubsection{Relationship between temporal standard error and emotional assessment}

To further analyze the link between the time judgment of emotional stimuli and their affective assessment thorough each trial, we ran linear
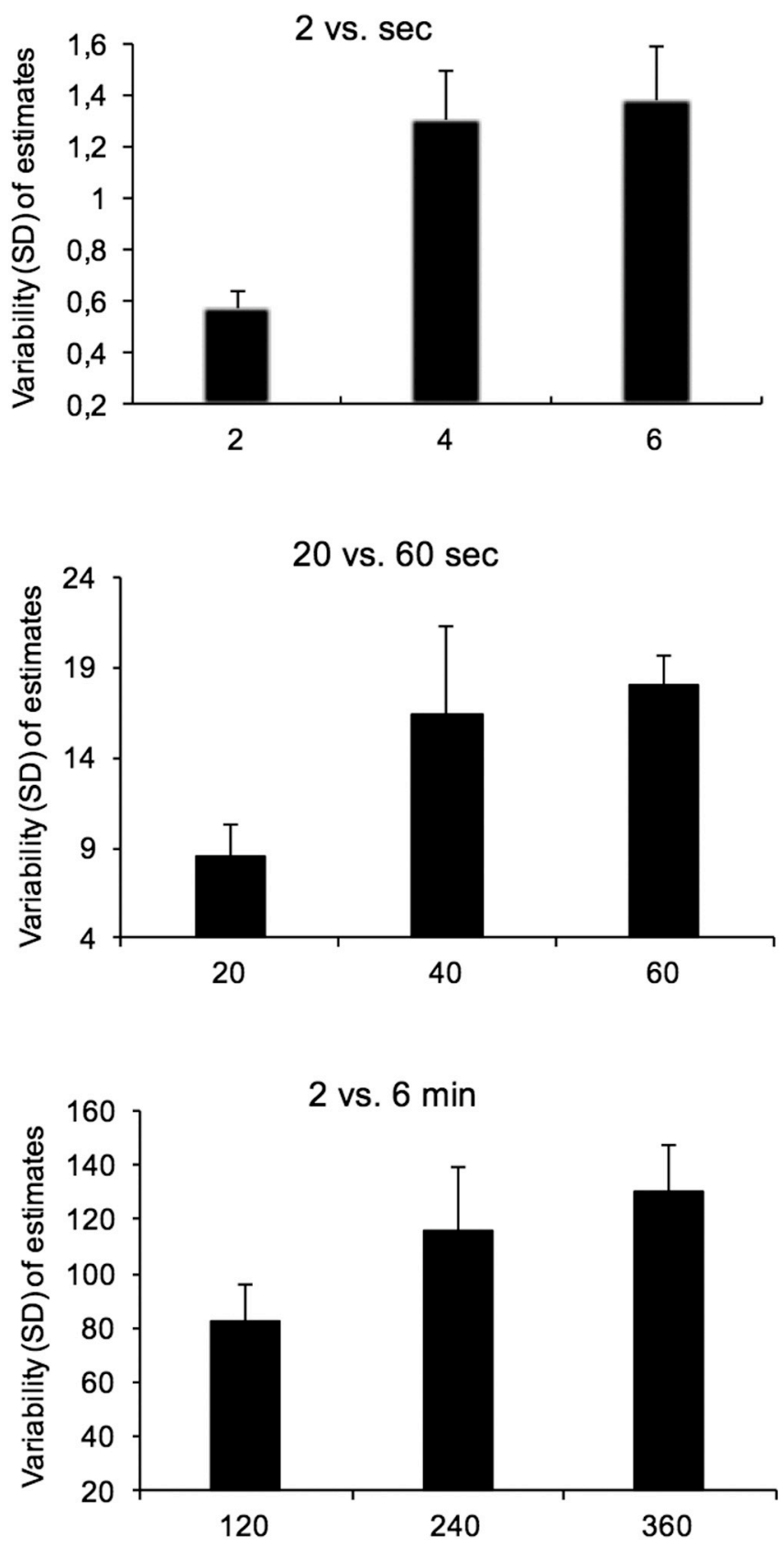

Fig. 5. Temporal variability (SD) of time estimates for the different stimulus durations for the 2 vs. $6-\mathrm{sec}$, the 20 vs. $60-\mathrm{sec}$, and the 2 vs. 6 -min duration groups.

mixed model analyses (LMM) as there were multiple non-independent responses for the same subject for each trial. We thys conducted LMM
analyses with the temporal standard error as dependent variable, and

the duration range and the valence scores or the arousal scores entered as a fixed factor in the model. The subjects were considered as a random effect. The results of the LMM analyses are reported in Table 1. The statistical analyses on the affects experienced on each trial allowed us to
reveal a significant effect of arousal level and of emotional valence, which occurred independently of the duration range (Arousal:

$\mathrm{E}=0.0465, \mathrm{SE}=0.00988,95 \% \mathrm{Cl}[0.0271 ; 0.0659], t=4.707$, $p<.001$; Valence $\mathrm{E}=0.0549, \mathrm{SE}=0.0105,95 \% \mathrm{Cl}[0.0343 ; 0.0755]$, $t=5.23, p<.001)$. There was indeed a main effect of duration range $(p<.001)$ but no significant interaction between the duration range and the valence or the arousal scores $(p>.05)$. Consequently, as illustrated in Fig. 6, the overestimation of time tended to increase as the 
Table 1

Results of linear mixed model analyses on the time judgment (temporal standard error) with the arousal or/and the valence and the duration range as fixed effect factor.

\begin{tabular}{lcccccc}
\hline Names & Estimate & SE & LLCl & ULCl & $t$ & $p$-Value \\
\hline Intercept) & 0.26 & 0.04 & 0.19 & 0.34 & 6.97 & $<0.001$ \\
Arousal & 0.05 & 0.01 & 0.03 & 0.07 & 4.71 & $<0.001$ \\
Duration & 0.31 & 0.05 & 0.22 & 0.39 & 6.75 & $<0.001$ \\
Arousal $\times$ duration & -0.01 & 0.01 & -0.03 & 0.02 & -0.50 & .62 \\
(Intercept) & 0.27 & 0.04 & 0.19 & 0.34 & 7.23 & $<0.001$ \\
Valence & 0.06 & 0.01 & 0.03 & 0.08 & 5.23 & $<0.001$ \\
Duration & 0.29 & 0.04 & 0.20 & 0.37 & 6.48 & $<0.001$ \\
Valence $\times$ duration & -0.01 & 0.01 & -0.03 & 0.03 & -0.01 & .99 \\
(Intercept) & 0.25 & 0.05 & 0.16 & 0.34 & 5.35 & $<0.001$ \\
Arousal & -0.02 & 0.02 & -0.06 & 0.02 & -1.17 & 0.24 \\
Valence & 0.07 & 0.02 & 0.03 & 0.11 & 3.35 & $<0.001$ \\
Duration & -0.17 & 0.03 & -0.23 & -0.11 & -5.83 & $<0.001$ \\
Arousal $\times$ valence & 0.01 & 0.01 & -0.01 & 0.01 & 0.79 & .43 \\
Ar. $\times$ Val. $\times$ Du. & -0.01 & 0.01 & -0.01 & 0.01 & -0.40 & .69 \\
\hline
\end{tabular}

arousal level and the negative valence felt by the participants increased, and this for all durations. This was verified in the correlation analyses showing the increase in time estimates with the increase in the selfreported level of arousal $(R=0.28, p<.0001)$ and the emotional valence $(R=0.10, \mathrm{p}=.007)$. Furthermore, and regardless of the affective feeling, the time estimates increased with the length of the durations. However, when the valence and arousal scores were included in the same statistical model (Table 1), emotional valence appeared to be the best emotional predictor of the variance in time estimates $(\mathrm{E}=0.07117, \mathrm{SE}=0.02126,95 \% \mathrm{Cl}[0.02950 ; 0.11284], t=3.347$, $p<.001$.

Our study therefore replicated the results of studies on emotion using short durations by showing an overestimation of short durations for the HA emotional stimuli compared to the MA and the LA emotional stimuli. No difference was observed between the MA and the LA emotional stimuli. However, the originality of our study was to find similar time distortions for longer durations of several minutes. Our results nevertheless suggest that the emotion-related time distortions tended to decrease with the long stimulus durations due to a decrease in the intensity of affects over time. Consequently, the significance of the effect of emotion on the timing of long durations appeared higher when the scores for individual trials were analyzed than when we analyzed the average scores on trials. Our finding thus confirmed that the time judgment of emotional stimuli depends on the temporal dynamic of affective feelings.

Finally, we can assume that the effect of emotion on the judgment of long durations of several minutes depends mainly on the intensity of the emotional state induced by the emotional stimuli and its maintenance over time. However, the intensity of the emotion and its dynamic evolution over time are related (Waugh et al., 2010). Therefore, we conducted a second Experiment aimed at replicating the results found in Experiment 1 for the longest duration range (between 2 et $6 \mathrm{~min}$ ) but under experimental conditions that more fully take account of the ephemeral nature of the emotion. We therefore decided to reduce the length of the test session. Indeed, the exposure to emotional stimuli was particularly long in Experiment 1 involving both long and repetitive stimulus durations, with the session comprising 45 trials. The habituation of the participants to emotional stimuli may therefore have helped bring about a reduction in the effect of emotion on timing, even though it remained significant in our study. To this end, the intermediate arousal value of the emotional stimuli was no longer used, especially since the results of Experiment 1 showed that this distinction is not appropriate as we failed to find any differences in time judgment between the MA and LA emotional stimuli. In Experiment 2, in line with most emotion-related studies, only the HA and the LA emotional stimuli were used. In addition, the number of stimulus durations to be estimated was limited by randomly choosing stimulus durations in the tested duration range.

\section{Experiment 2}

\subsection{Method}

\subsubsection{Participants}

The sample comprised 32 (22 female) new students from Clermont Auvergne University $\left(\mathrm{M}_{\text {age }}=26.84, S D=5.77\right)$. They each provided their written informed consent to participate in this experiment. The statutory ethics committee (CPP, France) approved the procedure.

\subsubsection{Material and procedure}

The material and the procedure were similar to those used in Experiment 1 for the 2/6-min condition, except for the emotional stimuli used and the interval durations tested. In Experiment 2, we only used the HA and LA sounds. In addition, for each trial, the stimulus duration was randomly chosen between $2(\geq)$ and $6 \mathrm{~min}(\leq)$. The participants were explicitly told that the durations to be estimated would be between 1 and $12 \mathrm{~min}$. There were six trials altogether, with three trials for each emotional condition. On each trial, the participants
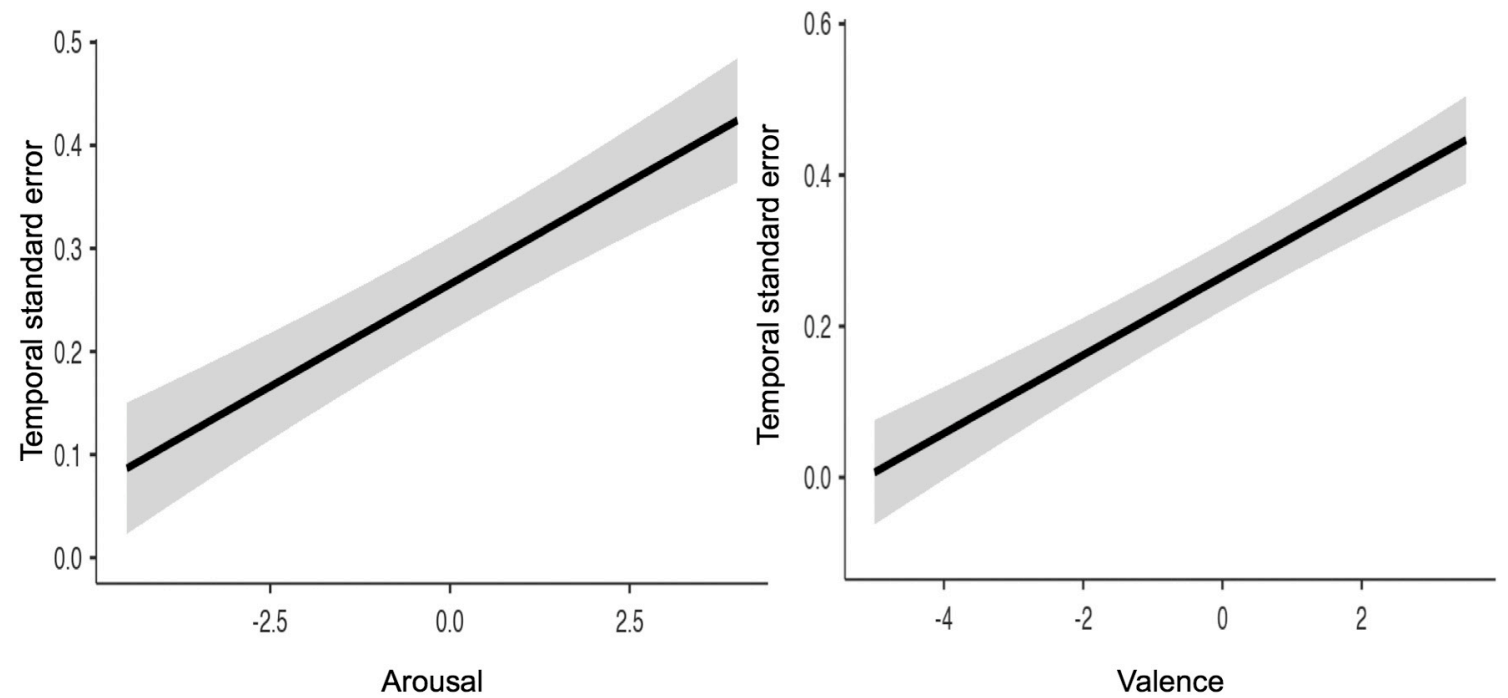

Fig. 6. Regression curve between temporal standard errors and arousal scores and valence scores. 

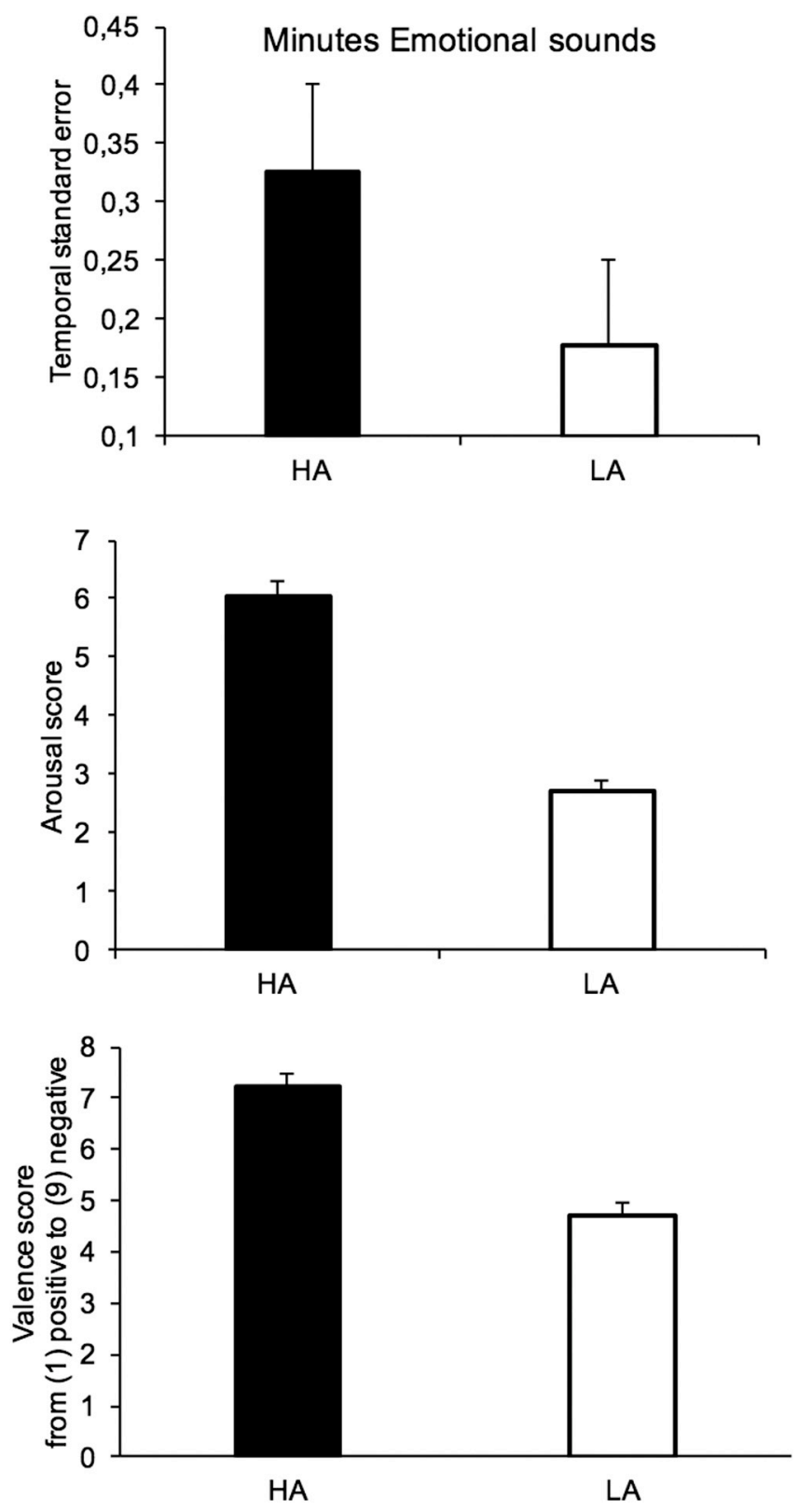

Fig. 7. Temporal standard error, arousal and valence scores for the HighArousal (HA) and the Low-Arousal (LA) emotional stimuli (sounds) in the minutes duration range condition.

therefore estimated the duration of the emotional stimulus as well as the level of arousal and pleasure experienced.

\subsection{Results and discussion}

Fig. 7 shows the average of the temporal standard error (top), arousal scores (middle) and emotional valence (pleasure) scores (bottom) for the HA and LA emotional stimuli. The ANOVA performed on the mean scores of arousal and displeasure confirmed that the HA emotional stimuli were judged to be more arousing and less pleasant than the LA emotional stimuli $\left(F(1,30)=133.62, p=.0001, \eta^{2}\right.$ $\overline{\text { p }} 0.82 ; F(1,30)=83.69, p=.0001, \eta^{2}={ }_{p} 0.74$, respectively). In line with these results, there was a significant effect of emotion on temporal judgment, $F(1,31)=10.34, p=.003, \eta_{p}^{2}=0.25$. The duration of the HA emotional stimuli was judged to be longer than that of the LA emotional stimuli, even though the durations were overestimated generally $(M=0.24, S E=0.7, t(31)=3.63, p=.001)$.
The LMM analyses on the time judgment for each trial, with either the arousal scores or the emotional valence scores used as fixed effect and the subjects as random effect, confirmed the significant link between the time judgment and the affective scores (Arousal: $E=0.0423$, $\mathrm{SE}=0.0112,95 \% \mathrm{Cl}[0.0202 ; 0.0643], t=3.76, p<.001$; Valence: $\mathrm{E}=0.0438, \mathrm{SE}=0.0126,95 \% \mathrm{Cl}[0.019 ; 0.0686], t=3.47$, $p<.001)$. When these two factors were entered in the same model, the arousal scores appeared to be the most reliable predictor of time distortions $(E=0.0288, S E=0.0148,95 \% \mathrm{Cl}[-1.91 \mathrm{e}-4 ; 0.0579]$, $t=1.95, p=.05)$.

In conclusion, the results of Experiment 2, using a shorter experimental session which was more appropriate for testing emotion with long durations, replicated those of Experiment 1. The durations of several minutes were indeed judged to be longer for the HA than for the LA emotional stimuli. In addition, the regression analyses established a significant link between subjective arousal and time distortions. The more aroused the participants felt due to the emotional stimuli, the more they overestimated their durations.

In Experiments 1 and 2, we tested specific auditory emotional stimuli created from the sounds in the IADS. In Experiment 3, we verified our results on the judgment of long durations with other emotional stimuli, i.e., 3D virtual reality (VR) films. VR films were used to maintain a sufficiently intense emotional level for the long periods tested. The procedure used was similar to that used in Experiment 2, except that the participants watched an emotional film through virtual reality glasses.

\section{Experiment 3}

\subsection{Method}

\subsubsection{Participants}

The sample consisted of 35 new students from Clermont Auvergne University $\left(\mathrm{M}_{\text {age }}=20, S D=3.01\right)$. They signed a written consent form to participate in this study, which used a procedure approved by the recent formed Research Ethics Committee of Clermont Auvergne University (IRB-UCA).

\subsubsection{Material}

An initial experiment was conducted on 18 participants to select the VR movies. A set of 11 films were tested on different self-reported dimensions via a questionnaire composed of 12 questions and a 9-point response scale for each question. Questions 1 and 2 related to the level of arousal (from Calm to Excited) and pleasure experienced (from Happy/Satisfied to Unhappy/Annoyed), respectively. Questions 3 and 4 were on the presence (feeling of being in the real world) and the quality of the VR films, and the other seven questions related to the realism of the films. These final questions constituted the realism subscale of the presence questionnaire (Witmer, Jerome, \& Singer, 2005). Three HighArousing VR films and three Low-Arousing VR films were then selected on the basis of the questionnaire data (Table 2). The HA-VR movies were: (HA-VR1) The Clown film from Amaze VR videos; (HA-VR2) The Fright test film from Within VR videos; (HA-VR3) The Killer film from VeeR VR videos. The LA-VR movies were: (LA-VR1) The Dolphin Man: Breathe film from Within VR videos; (LA-VR2) The Hawaii Beach film from Stream Home VR; (LA-VR3) The Submit Pavilion film from Steam Home VR.

The participant stood at a location marked by a cross on the floor of a laboratory room. He/she wore virtual reality glasses (HTC Vive Steam VR) and an audio headphone, both connected to a computer (Dell Precision Tower 5810) that played the VR film via the Stream-VR and Viveport software. Another computer (Vaio Sony), running the E-prime II software, allowed the experimenter to control the experimental events and record the participant's responses. For each interval duration, two beeps were emitted by this computer, one for the onset and the other for the offset of the interval. On each beep, the experimenter, 
Table 2

Results of the assessment of material used in Experiment 3: The threeVirtual Reality movies used for the High-Arousal and the Low-Arousal emotional stimuli.

\begin{tabular}{|c|c|c|c|c|c|c|c|}
\hline & & \multicolumn{3}{|c|}{ HA-VR movies } & \multicolumn{3}{|c|}{ LA-VR movies } \\
\hline & & HA-VR1 & HA-VR2 & HA-VR3 & LA-VR1 & LA-VR2 & LA-VR3 \\
\hline \multirow[t]{2}{*}{ Arousal } & M & 8.00 & 7.50 & 6.35 & 2.06 & 2.59 & 3.22 \\
\hline & $S D$ & 0.97 & 1.15 & 1.99 & 0.87 & 1.46 & 2.51 \\
\hline \multirow[t]{2}{*}{ Valence } & M & 7.17 & 6.19 & 6.35 & 2.78 & 2.94 & 3.22 \\
\hline & $S D$ & 2.04 & 2.69 & 2.03 & 1.48 & 1.71 & 2.29 \\
\hline \multirow[t]{2}{*}{ Presence } & $M$ & 5.06 & 5.44 & 5.65 & 5.94 & 5.35 & 6.83 \\
\hline & $S D$ & 2.75 & 2.10 & 1.90 & 2.58 & 2.74 & 3.37 \\
\hline \multirow[t]{2}{*}{ Quality } & $\mathrm{M}$ & 4.17 & 3.81 & 4.06 & 3.44 & 3.94 & 3.63 \\
\hline & $S D$ & 2.71 & 2.46 & 2.61 & 2.45 & 2.56 & 2.25 \\
\hline \multirow[t]{2}{*}{ Realism } & M & 43.66 & 39.63 & 39.18 & 40.17 & 37.88 & 41.72 \\
\hline & $S D$ & 11.39 & 12.75 & 13.87 & 12.53 & 16.27 & 16.06 \\
\hline
\end{tabular}

who stayed next to the participant, touched his/her arm with a pen to indicate the interval duration to be estimated. The participants performed three demonstration trials to allow them to understand the task and to familiarize them with the VR environment. The demonstration trials were conducted with another VR film (The Blu: whale encounter from Werv VR).

\subsubsection{Procedure}

The procedure was similar to that used in Experiment 2, except for the emotional stimuli used (3D virtual reality videos) and certain experimental arrangements made necessary by the use of VR. The participants were thus given six trials: three trials with the HA emotional stimuli (films) and three trials with the LA emotional stimuli. The interval duration to be estimated was randomly chosen between $2(\geq)$ and $6 \mathrm{~min}(\leq)$. The participant wore the VR glasses and the audio headphones for each trial. When the participant was ready, the experimenter initiated the trial by pressing the computer's spacebar. After a random delay of between 5 and $15 \mathrm{~s}$, the two auditory stimuli were output separated by the target interval duration. Immediately after each stimulus, the experimenter touched the participant's arm. The participants gave their temporal judgment orally, as well as their affective assessment (arousal, emotional valence (pleasure)) of the VR films seen during the interval to be estimated.

\subsection{Results and discussion}

Fig. 8 shows the average of the temporal standard error(top), arousal scores (middle) and emotion valence (pleasure) scores (bottom) for the HA and the LA emotional stimuli. The ANOVA on the affective scores confirmed that the participants judged the HA emotional stimuli to be more arousing and unpleasant $\left(M_{\text {arousal }}=8.13, S E_{\text {arousal }}=0.139\right.$; $\left.M_{\text {pleasure }}=7.52, S E_{\text {pleasure }}=0.26\right)$ than the LA emotional stimuli

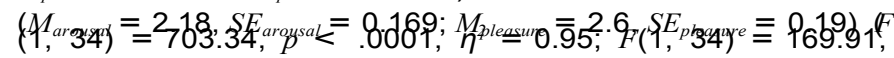
$p<.0001, \eta^{2}$

${ }_{p}=0.83$, respectively). In addition, the interval duration was judged longer with the HA emotional stimuli $(M=0.507$, $S E=0.096)$ than with the LA emotional stimuli $(M=0.345$, $S E=0.066), F(1,34)=4.70, p=.037,{ }_{p} \eta^{2}=0.12$.

The LMM analysis performed on the time judgment on each trial, with arousal scores or emotional valence scores as fixed factor and the subjects as random effect, confirmed the significant relationship between the time judgment and both the arousal scores $(E=0.0281$, $\mathrm{SE}=0.0088,95 \% \mathrm{Cl}[0.0108 ; 0.0454], t=3.18, p=.002)$ and the emotional valence scores $(E=0.0394, \mathrm{SE}=0.0101,95 \% \mathrm{Cl}[0.0196$; 0.0592], $t=3.91, p<.001)$. When these two factors were entered in the same model, their interaction contributed significantly to explaining the variance in time distortions (Arousal $\times$ Valence: $\mathrm{E}=0.01981$, SE $=0.00696,95 \% \mathrm{Cl}[0.00617 ; 0.0334], t=2.85$,
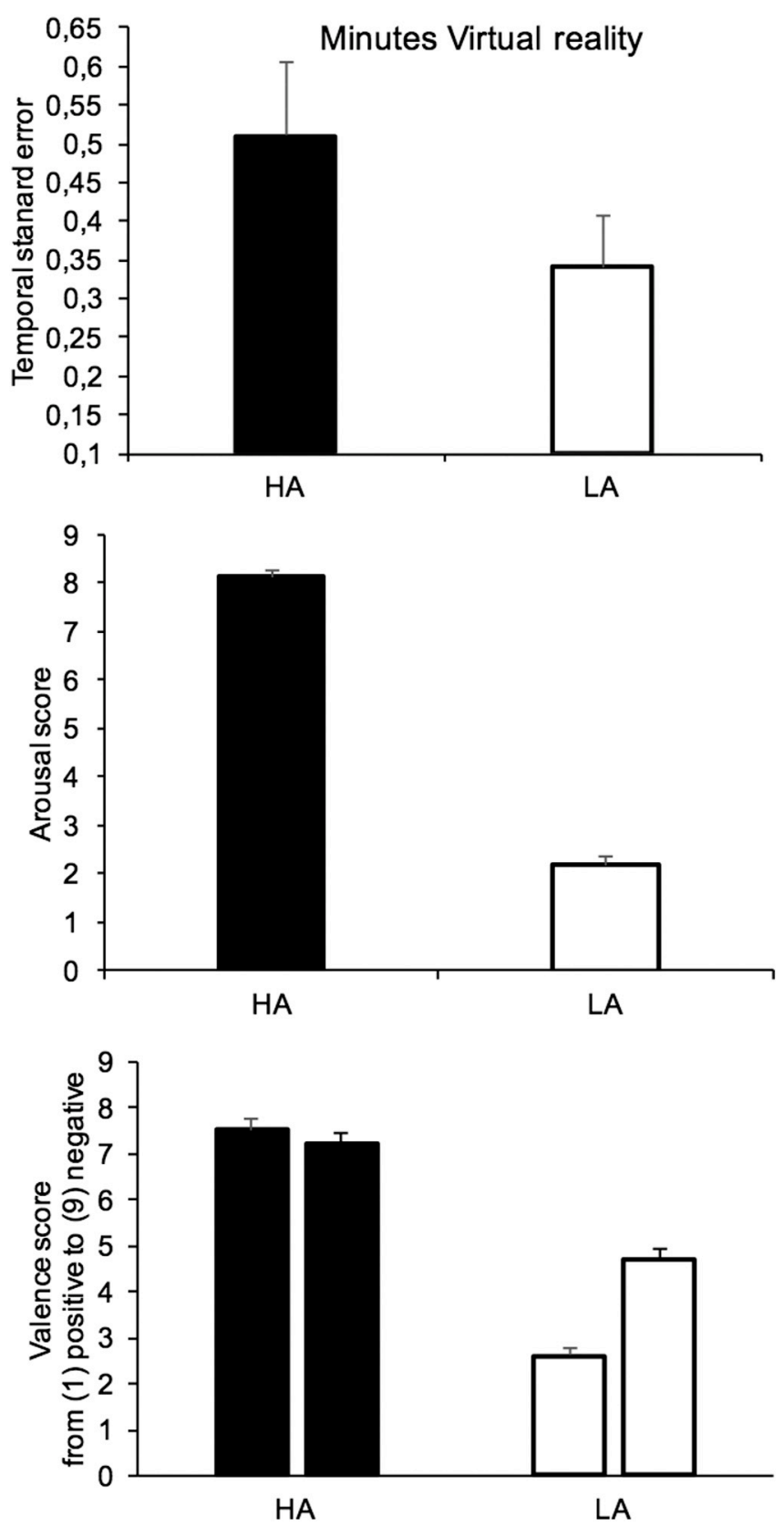

Fig. 8. Temporal standard error, arousal and valence scores for the HighArousal (HA) and the Low-Arousal (LA) emotional stimuli (virtual reality film) in the minutes duration range condition.

$p=$ THedfective states reported by the participants when they saw the

VR films were thus significant predictors of time distortions for the long duration of several minutes. In conclusion, although the emotional stimuli used in Experiment 3 were different from those used in Experiments 1 and 2, the results were similar, with the duration of $\mathrm{HA}$ emotional stimuli being further overestimated compared to that of LA emotional stimuli in the range of durations of several minutes.

\section{General discussion}

Three experiments were conducted on the time judgment of emotional stimuli over a wide range of durations going from $2 \mathrm{~s}$ to $6 \mathrm{~min}$, and with two types of emotional stimuli (emotional sounds and VR films). The results of these three experiments are entirely consistent, 
showing that the duration of HA emotional stimuli was systematically judged longer than that of LA emotional stimuli, and this for the long durations of several minutes as well as for the shorter durations of a few seconds. In addition, the magnitude of temporal lengthening increased with the subjective level of emotional arousal. The more aroused the participants reported themselves to be by the perception of emotional stimuli, the longer they judged the associated durations. Therefore, our studies demonstrate that changes in affective states produce a subjective lengthening of the perceived duration of emotional events for all durations.

Our experiments suggest that any increase in subjective arousal lengthens perceived duration. They thus provide additional data for the growing body of evidence confirming the key role of changes of arousal in time distortions (e.g., Cheng et al., 2016; Fayolle et al., 2015; Lake et al., 2016; Mella et al., 2010). Everything suggests that the lengthening of perceived durations under the influence of threat or stress results from the increase of arousal level, which speeds up the internal clock system underlying the representation of time. The role of arousal in time distortions observed for short durations has therefore also been verified for long durations. However, this was observed in our studies when the emotional stimulus was present during the interval duration (sound, film), and when it remained sufficiently arousing throughout the entire interval. Indeed, our results indicated differences in time estimates between the highly arousing stimuli and the other stimuli, but not between the moderately and the weakly arousing emotional stimuli. Furthermore, they showed that the magnitude of the time distortions was directly related to the arousal level experienced by the participants. As observed in Experiment 1 which used a long series of repetitive trials inducing habituation phenomena, the time distortions decreased when the subjective arousal level decreased. And when the arousal level remained stable with low exposure to emotional stimuli, as in Experiments 2 and 3 , the time distortions persisted for the long durations.

Several studies have found that the emotion-based temporal effect disappears beyond $4 \mathrm{~s}$ when participants are presented with emotional pictures (Angrilli et al., 1997; Bar-Haim et al., 2010). This explains why most studies have simply tested short durations in the range of seconds. However, our studies demonstrate that effects of emotion on time estimates can be observed beyond $4 \mathrm{~s}$, when the state of stress or threat is maintained over time. This is consistent with the idea that although the effect of arousal on exposure to emotional stimuli is transient, it can be prolonged in some conditions (Stirling \& Elliott, 2010). However, for the long durations of several minutes, we can question the nature of the emotional mechanisms involved in time distortions. As reported in the introduction, some recent studies have collected physiological indexes of the activity of the autonomic nervous system and found correlations between physiological arousal and time distortions that are restricted to short durations only (Ogden et al., 2019; Piovesan et al., 2018; van Hedger et al., 2017). The authors therefore concluded that the effect of physiological arousal is limited to the time of the threat. The threat or the stress would therefore have been longer in our experiments when the participants heard continuous sounds or were immersed in a VR environment. Further experiments are nevertheless needed to analyze the fluctuation of physiological activity during a long temporal interval and its effect on timing with these continuous emotional stimuli.

In our studies, we did not record physiological indexes of arousal, but we did assess subjective arousal and subjective emotional valence on each trial. The self-reported affects are considered as validated measures of emotion. Ledoux and Hofmann (2018, p. 69) explained that "behavioral, physiological and subjective responses are all products of the same system". The self-reported affects are indeed correlated with physiological emotional reactions (Lang et al., 1999). However, and more convincingly, as Barrett says (2006, p. 41), "it is not possible to confidently claim that there are kinds of emotion with unique and invariant autonomic signatures". Emotion cannot be reduced to a simple immediate reaction to an emotional stimulus (threatening stimulus), caused by a dedicated mechanism. It instead emerges from an ongoing constructive process (which therefore evolves over time) that involves a set of psychological "ingredients" (Barrett, 2013; Lindquist et al., 2013). We assume that this would be especially true for the time distortions observed in the case of long durations when physiological arousal decreases or no longer has any significant effect.

Our results based on verbal self-reported emotions suggest that time distortions for long durations are linked to the subjective perception of affects. As suggested above, the early physiological arousal-based effect that speeds up the internal clock and produces a lengthening of perceived time for short durations (bottom-up process) could be prolonged over time under the presence of high-arousal stimuli. However, over the course of time, it might also give way to a conscious level of arousal (a subjective assessment of one's emotions) (top-down process) that would help to maintain or even prolong a certain level of stress and anxiety influencing the timing of long durations (Droit-Volet, 2019; Droit-Volet et al., 2015). Many studies have shown the strength of the mind that can prolong fear or anxiety, or even produce these emotions in the absence of threatening emotional stimuli. Consequently, over time, there may be a shift from an automatic physiological arousal mechanism to a conscious arousal mechanism. In other words, the emotions are passions of short duration that can be prolonged by the mind. In line with this idea, some studies have shown that the awareness of the speed of the passage of time depends on the conscious affect for long durations (Droit-Volet et al., 2018) and participants would not be aware of the effects of high-arousal emotion on the timing for short durations (Lamotte et al., 2014). However, as suggested our findings, the time distortions in response to negative high-arousal emotions would be outwardly similar (lengthening effect) regardless of the durations - short or long - (lengthening effect), even if the internal (automatic or conscious) processes differ.

Our results showed that the time distortions for the long durations were significantly related to subjective arousal but also to pleasure. These two core dimensions of emotion are closely correlated (Russell, 2003; Scherer, 2005). Consistently with this idea, the time distortions observed in Experiment 3 with the VR movies were explained by the interaction between subjective arousal and subjective emotional valence. However, in Experiment 1, subjective emotional valence was a better predictor of time distortions than subjective arousal. This supremacy of the emotional valence over the arousal level for the temporal lengthening of time provides additional support for the idea described above that conscious cognitive processes presumably occur during the passage of time and come to modulate or replace earlier basic physiological mechanisms of arousal. The mechanisms underlying temporal distortions under emotion could therefore change with the length of the durations, even if a similar type of time distortion is always observed. In future research, it would be interesting to further examine when and how the different components of emotions change the nature of temporal processing over time.

In conclusion, although the mechanisms underlying the effects of emotion on time distortions for long durations were not identified in our studies, our results clearly demonstrated that the perception of HA emotional stimuli produced time distortions in the form of a lengthening effect for very long durations lasting several minutes, as well as for short durations. It also showed that the magnitude of the lengthening of the directly perceived duration increased with the individual feeling of being aroused in stressful conditions.

\section{Funding}

This work was supported by a grant (TIMESTORM) from the European Commission's Horizon 2020 research and innovation framework program (H2020-FETPROACT-2014).

\section{CRediT authorship contribution statement}

Sylvie Droit-Volet: Conceptualization, Methodology, Validation, 
Formal analysis, Resources, Data curation, Writing - original draft, Visualization, Supervision, Project administration, Funding acquisition. Ahmed El-Azhari: Methodology, Investigation, Formal analysis. Samuel Haddar: Methodology, Software, Investigation, Formal analysis. Rémi Drago: Methodology, Software, Investigation, Formal analysis. Sandrine Gil: Conceptualization, Methodology, Formal analysis, Writing - review \& editing, Visualization.

\section{Acknowledgments}

The author thanks Solenne Debey (master student), Sophie Monceau and Sophie Fayolle (research assistant) for helping us to collect the data.

\section{References}

Angrilli, A., Cherubini, P., Pavese, A., \& Manfredini, S. (1997). The influence of affective factors on time perception. Perception \& Psychophysics, 59, 972-982.

Bar-Haim, Y., Kerem, A., Lamy, D., \& Zakay, D. (2010). When time slows down: The influence of threat on time perception in anxiety. Cognition \& Emotion, 24(2), 255263.

Barrett, L. F. (2006). Are emotions natural kinds? Perspectives on Psychological Science, I(1), 28-58.

Barrett, L. F. (2013). Psychological construction: The Darwinian approach to the science of emotion. Emotion Review, 5(4), 379-389.

Bradley, M. M., \& Lang, P. J. (1994). Measuring emotion: The self-assessment manikin and the semantic differential. Journal of Behavior Therapy and Experimental Psychiatry, 25(1), 49-59.

Bradley, M. M., \& Lang, P. J. (2007). The international affective digitized sounds (2nd edition; IADS-2): Affective ratings of sounds and instruction manual. Technical report B-3. Gainesville, FL: University of Florida.

Buetti, S., \& Lleras, A. (2012). Perceiving control over aversive and fearful events can alter how we experience those events: An investigation of time perception in spiderfearful individuals. Frontiers in Psychology, 3, 337. https://doi.org/10.3389/fpsyg. 2012.00337.

Cheng, R. K., Tipples, J., Narayanan, N. S., \& Meck, W. H. (2016). Commentary-Clock speed as a window into dopaminergic control of emotion and time perception. Timing \& Time Perception, 4(1), 99-122.

Cocenas-Silva, R., Droit-Volet, S., \& Gherardi-Donato, E. C. S. (2019). Chronic stress impairs temporal memory. Timing \& Time Perception, 7(2), 108-130.

Doi, H., \& Shinohara, K. (2009). The perceived duration of emotional face is influenced by the gaze direction. Neuroscience Letters, 457(2), 97-100.

Droit-Volet, S. (2016). Emotion and implicit timing. PLoS One, 11(7), Article e0158474. https://doi.org/10.1371/journal.pone.0158474.

Droit-Volet, S. (2019). The temporal dynamic of emotional effect on judgments of durations. In V. Arstila, A. Bardon, S. Power, \& A. Vatakis (Eds.). The illusions of time: Philosophical and psychological essays on timing and time perception. Basingstoke: Palgrave Macmillan.

Droit-Volet, S., \& Berthon, M. (2017). Emotion and implicit timing: The arousal effect. Frontiers in Psychology, 8, 176. https://doi.org/10.3389/fpsyg.2017.00176.

Droit-Volet, S., Brunot, S., \& Niedenthal, P. (2004). Perception of the duration of emotional events. Cognition \& Emotion, 18(6), 849-858.

Droit-Volet, S., Fayolle, S., \& Gil, S. (2011). Emotional state and time perception: Mood elicited by films. Frontiers in Integrative Neuroscience, 5, 33. https://doi.org/10.3389/ fnint.2011.00033.

Droit-Volet, S., Fayolle, S., Lamotte, M., \& Gil, S. (2013). Time, emotion and the embodiment of timing. Timing and Time Perception, l(1), 99-126.

Droit-Volet, S., Fayolle, S., \& Gil, S. (2016). Emotion and time perception in children and adults: The effect of task-difficulty. Timing and Time Perception, 4(1), 7-29.

Droit-Volet, S., \& Gil, S. (2016). The emotional body and time perception. Cognition \& Emotion, 30(4), 687-699.

Droit-Volet, S., Lamotte, M., \& Izaute, M. (2015). The conscious awareness of time distortions regulates the effect of emotion on the perception of time. Consciousness \& Cognition, 38, 155-164.

Droit-Volet, S., \& Meck, W. H. (2007). How emotions colour our time perception. Trends in Cognitive Sciences, I(12), 504-513.

Droit-Volet, S., Monceau, S., Berthon, M., Trahanias, P., \& Maniadakis, M. (2018). The explicit judgment of long durations of several minutes in everyday life: Conscious retrospective memory judgment and the role of affects? PLoS One, 13(4), Article e0195397.

Falk, J. L., \& Bindra, D. (1954). Judgment of time as a function of serial position and stress. Journal of Experimental Psychology, 39, 327-331.

Fayolle, S., Gil, S., \& Droit-Volet, S. (2015). Fear and time: Fear speeds up the internal clock. Behavioural Processes, 120, 135-140.

Gil, S., \& Droit-Volet, S. (2011). Time flies in the presence of angry faces, depending on the temporal task used!. Acta Psychologica, 136(3), 354-362.

Gil, S., \& Droit-Volet, S. (2012). Emotional time distortions: The fundamental role of arousal. Cognition \& Emotion, 26(5), 847-862.

Gil, S., Niedenthal, P., \& Droit-Volet, S. (2007). Anger and temporal perception in children. Emotion, 7(1), 219-225.

Grommet, E. K., Droit-Volet, S., Gil, S., Hemmes, N. S., Baker, A. H., \& Brown, B. (2010).
Effects of a fear cue on time estimation in human observers. Behavioural Processes, 86 , $88-93$.

Guyau, M. (1890). La genèse de l'idée du temps. Paris: Félix Alcan.

Hare, R. D. (1963). The estimation of short temporal intervals terminated by shock. Journal of Clinical Psychology, 19(3), 378-380.

Kliegl, K. M., Limbrecht-Ecklundt, K., Dürr, L., Traue, H. C., \& Huckauf, A. (2015). The complex duration perception of emotional faces: Effects of face direction. Frontiers in Psychology, 6, 262. https://doi.org/10.3389/fpsyg.2015.00262.

Lake, J. I., LaBar, K. S., \& Meck, W. H. (2016). Emotional modulation of interval timing and time perception. Neuroscience \& Biobehavioral Reviews, I(64), 403-420.

Lake, J. L. (2016). Recent advances in understanding emotion-driven temporal distortions. Current Opinion in Behavioral Sciences, 8, 214-219.

Lambrech, A., Mella, N., Pouthas, V., \& Noulhiane, M. (2011). Subjectivity of time perception: A visual emotional orchestration. Frontiers in Integrative Neurosciences, 5, 73. https://doi.org/10.3389/fnint 2011.00073.

Lamotte, M., Chakroun, N., Droit-Volet, S., \& Izaute, M. (2014). Metacognitive questionnaire on time: Feeling of passage of time. Timing and Time Perception, 2(3), 339-359.

Lang, P. J., Bradley, M. M., \& Cuthbert, B. N. (1999). International affective picture rating system (IAPS): Instruction manual and affective ratings. Technical report $A-4$. Gainesville, FL: Center for Research in Psychophysiology, University of Florida.

Langer, J., Wapner, S., \& Werner, H. (1961). The effect of danger upon the experience of time. American Journal of Psychology, 74, 94-97.

LeDoux, J. E., \& Hofmann, S. G. (2018). The subjective experience of emotion: A fearful view. Current Opinion in Behavioral Sciences, 19, 67-72

Lee, K.-H., Seelam, K., \& O'Brien, T. (2011). The relativity of time perception produced by facial emotional stimuli. Cognition \& Emotion, 25(8), 1471-1480.

Lindquist, K. A., Siegel, E. H., Quigley, K. S., \& Barrett, L. F. (2013). The hundred-year emotion war: Are emotions natural kinds or psychological constructions? Comment on Lench, Flores, and Bench (2011). Psychological Bulletin, 139(1), 255-263.

Liu, P., Yang, W., Yuan, X., Bi, C., Chen, A., \& Huang, X. (2015). Individual alerting efficiency modulates time perception. Frontiers in Psychology, 6, 386. https://doi.org/ 10.3389/fpsyg.2015.00386.

Matell, M. S., \& Meck, W. H. (2004). Cortico-striatal circuits and interval timing: Coincidence detection of oscillatory processes. Cognitive Brain Research, 21(2), 139-170.

Mauss, I. B., \& Robinson, M. D. (2009). Measures of emotion: A review. Cognition and Emotion, 23(2), 209-237.

Mella, N., Conty, L., \& Pouthas, V. (2010). The role of physiological arousal in time perception: Psychophysiological evidence from an emotion regulation paradigm. Brain Cognition, 75(2), 182-187.

Noulhiane, M., Mella, N., Samson, S., Ragot, R., \& Pouthas, V. (2007). How emotional auditory stimuli modulate time perception. Emotion, 7(4), 697-704.

Ogden, R. S., Henderson, J., McGlone, F., \& Richter, M. (2019). Time distortion under threat: Sympathetic arousal predicts time distortion only in the context of negative highly arousing stimuli. PLosOne, 14(5), Article e0216704.

Piovesan, A., Mirams, L., Poole, H., Moore, D., \& Ogden, R. S. (2018). The relationship between pain induced autonomic arousal and perceived duration. Emotion, 19(7), $1148(1161)$.

Rattat, A. C., \& Droit-Volet, S. (2012). What is the best and easiest method of preventing counting in different temporal tasks? Behavior Research Methods, 44, 67-80.

Rau, P. L. P., Peng, S. Y., \& Yang, C. C. (2006). Time distortion for expert and novice online game players. Cyberpsychology \& Behavior, 9(4), 396-403.

Russell, J. A. (2003). Core affect and the psychological construction of emotion Psychological Review, 110(1), 145-172.

Scherer, K. R. (2005). What are emotions? And how can they be measured? Social Science Information, 44(4), 695-729.

Scherer, K. R., \& Moors, A. (2019). The emotion process: Event appraisal and component differentiation. Annual Review of Psychology, 70, 719-745.

Simen, P., \& Matthew, M. (2016). Why does time seem to fly we'are having fun?: Increased dopamine may cause our internal clock to slow down, creating a sense of speeding time. Science, 354(6317), 1231-1232.

Soares, S., Atallah, B., \& Paton, J. P. (2016). Mindbrain dopamine neurons control judgment of time. Science, 354(6317), 1273-1277.

Stirling, J., \& Elliott, R. (2010). Introducing neuropsychology. Hove: Psychology Press.

Thayer, S., \& Schiff, W. (1975). Eye-contacts, facial expression, and the experience of time. The Journal of Social Psychology, 95, 117-124.

Tipples, J. (2008). Negative emotionality influences the effects of emotion on time perception. Emotion, 8(1), 127-131.

Tipples, J. (2011). When time stands still: Fear-specific modulation of temporal bias due to threat. Emotion, 11(1), 74-80.

Tobin, S., Bisson, N., \& Grondin, S. (2010). An ecological approach to prospective and retrospective timing of long durations: A study involving gamers. PLoS One, 5(2), Article e9271.

Tobin, S., \& Grondin, S. (2009). Video games and the perception of very long durations by adolescents. Computers in Human Behavior, 25(2), 554-559.

van Hedger, K., Necka, E. A., Barakzai, A. K., \& Norman, G. J. (2017). The influence of social stress on time perception and psychophysiological reactivity. Psychophysiology, 54(5), 706-712.

Van Volkinburg, H., \& Balsam, P. (2014). Effects of emotional valence and arousal on time perception. Timing \& Time Perception, 2(3), 360-378.

Waugh, C. E., Hamilton, J. P., \& Gotlib, I. H. (2010). The neural temporal dynamics of the intensity of emotional experience. Neuroimage, 49(2), 1699-1707.

Wearden, J. H., \& Lejeune, H. (2008). Scalar properties in human timing: Conformity and violations. Quarterly Journal of Experimental Psychology, 61(4), 569-587.

Witmer, B. J., Jerome, C. J., \& Singer, M. J. (2005). The factor structure of the presence questionnaire. Presence, 14(3), 298-312. 